Rev. Bras. Saúde Prod. Anim., Salvador, v.17, n.3, p.413-423 jul./set., $2016 \quad$ http://www.rbspa.ufba.br

\title{
Farinha de cará (Dioscorea trifida L.) sobre o desempenho, qualidade do ovo e bioquímica sérica de poedeiras comerciais leves
}

\author{
Cará flour ("Dioscorea trifida” L.) on performance, egg quality and serum \\ biochemistry of commercial laying hens
}

\begin{abstract}
FEIJÓ, Julmar da Costa ${ }^{1}$; CRUZ, Frank George Guimarães ${ }^{1 *}$; MELO, Ramon Duque ${ }^{1}$; RUFINO, João Paulo Ferreira ${ }^{1}$; DAMASCENO, Jessica Lima ${ }^{1}$; COSTA, Ana Paula Guimarães Cruz ${ }^{1}$; NEGREIROS, Thatiane de Jesus Nogueira ${ }^{2}$
\end{abstract}

\author{
${ }^{1}$ Universidade Federal do Amazonas, Faculdade de Ciências Agrárias, Setor de Avicultura, Manaus, \\ Amazonas, Brasil. \\ ${ }^{2}$ Universidade Federal do Amazonas, Instituto de Ciências Sociais, Educação e Zootecnia, Parintins, \\ Amazonas, Brasil. \\ *Endereço para correspondência: frankgcruz@gmail.com
}

\section{RESUMO}

Esse trabalho foi desenvolvido com o objetivo de avaliar o desempenho, qualidade do ovo e bioquímica sérica de poedeiras comerciais leves submetidas a rações com níveis crescentes $(0,5$, $10,15,20$ e $25 \%$ ) de farinha de cará. Foram utilizadas 144 poedeiras da linhagem Hissex White com 39 semanas de idade. O experimento teve duração de 84 dias divididos em quatro períodos de 21 dias. O delineamento experimental foi $o$ inteiramente casualizado com seis tratamentos e quatro repetições de seis aves cada. As estimativas dos níveis de farinha de cará foram determinadas por meio de regressão polinomial. Os resultados de consumo de ração, produção de ovos, conversão alimentar (por dúzia de ovos e massa de ovos) e massa de ovo apresentaram diferenças significativas $(\mathrm{P}<0,05)$ observando-se efeito quadrático. As variáveis de qualidade do ovo não foram influenciadas significativamente $(\mathrm{P}>0,05)$ pela inclusão de farinha de cará nas rações. Foram observadas diferenças significativas $(\mathrm{P}<0,05)$ nas concentrações de triglicerídeos e $\mathrm{pH}$ sanguíneos apresentando efeito quadrático. A partir dos resultados encontrados, concluiu-se que a farinha de cará pode ser utilizada como alimento alternativo em rações de poedeiras comerciais leves, tendo o nível de 5\% de inclusão apresentado melhor desempenho e resultados de bioquímica sérica. Até $25 \%$ de inclusão, não houve alteração na qualidade do ovo.

Palavras-chave: alimento alternativo, consumo de ração, conversão alimentar, $\mathrm{pH}$, triglicerídeos

\section{SUMMARY}

This study was developed with the objective of to evaluate the performance, egg quality and biochemical parameters of increasing levels $(0 ; 5$; $10 ; 15 ; 20$ e $25 \%$ ) of cará flour in diets for laying hens. 144 birds Hissex White with 39 weeks of age were used. The experiment had duration of 84 days divided into four periods of 21 days. The experimental method was complete randomized with six treatments and four replications of six birds each. The estimates of cará flour levels were determined by polynomial regression. The results of feed intake, egg production, feed conversion (per dozen eggs and per egg mass), and egg mass showed significant differences $(\mathrm{P}<0.05)$ observed quadratic effect. The egg quality variables weren't influenced significantly $(\mathrm{P}>0.05)$ by the treatments. Significant differences were observed $(\mathrm{P}<0.05)$ in blood triglyceride and $\mathrm{pH}$ concentrations showed quadratic effect. From the results, concludes that the cará flour can be used as an alternative food in diets for laying hens, with the inclusion level of 5\% showed great results of performance and serum biochemistry. At $25 \%$ of inclusion, there wasn't change in egg quality.

Keywords: alternative feed, feed intake, feed conversion, $\mathrm{pH}$, triglycerides 


\section{INTRODUÇÃO}

A avicultura em algumas regiões do Brasil é prejudicada pela baixa disponibilidade de grãos. Em virtude da sazonalidade e dos preços de produtos como o milho e o farelo de soja, ingredientes que mais contribuem para a elevação dos custos de produção de aves, a busca por alimentos alternativos, principalmente subprodutos agroindustriais, tem sido crescente (JAFARI et al., 2006; LOPES et al., 2011).

As exigências atuais do consumidor por alimentos mais saudáveis e naturais também auxiliaram no incentivo do crescimento do número de pesquisas na área de nutrição animal com alimentos alternativos em substituição aos alimentos comumente utilizados nas rações, principalmente transgênicos e sintéticos, de modo a manter ou incrementar a produtividade, reduzir os custos (GARCIA \& DALE, 2006; GARCIA et al., 2009), e melhorar a qualidade deste produto final.

No contexto encontrado principalmente no Estado do Amazonas, com restrição de recursos e alto valor de matérias primas, as pesquisas com alimentos alternativos em rações para aves visam principalmente minimizar os custos com alimentação, tendo em vista que estes correspondem à cerca $70 \%$ dos custos totais de produção. E, em pesquisas com ingredientes alternativos para aves, a análise econômica dos resultados experimentais é muito importante, uma vez que produtores e especialistas poderão constituir critérios que irão contribuir para utilização dos mesmos de forma mais cautelosa e eficiente (SILVA et al., 2009; SANTOS \& GRANJEIRO, 2012).

Uma das alternativas em evidência com potencial para ser incluso nas rações para poedeiras é a farinha de cará (Dioscorea trifida L.), devido a crescente produção do cará na região amazônica. $\mathrm{O}$ cará é uma espécie de inhame comestível originária da América do Sul, que em conjunto com outras espécies importantes, economicamente do gênero Dioscorea, é mantida por pequenos agricultores tradicionais. Suas túberas apresentam na sua composição carboidratos, proteínas, sais minerais e vitaminas, bem como propriedades antimicrobianas, diuréticas e energizantes (RAMOS-ESCUDERO et al., 2010).

A partir destas informações, o presente trabalho teve como objetivo avaliar a inclusão de diferentes níveis crescentes de farinha de cará em rações de poedeiras comerciais leves sobre $\mathrm{o}$ desempenho, a qualidade do ovo e a bioquímica sérica.

\section{MATERIAL E MÉTODOS}

O experimento foi conduzido nas instalações do Setor de Avicultura do Departamento de Produção Animal e Vegetal da Faculdade de Ciências Agrárias da Universidade Federal do Amazonas- UFAM, localizado no Setor Sul do Campus Universitário, Manaus Amazonas.

O experimento foi realizando de outubro de 2014 a janeiro de 2015 dividido em quatro períodos de avaliação de 21 dias cada. Antes do período experimental, as aves foram submetidas a uma adaptação de sete dias as rações experimentais e as instalações.

$\mathrm{O}$ aviário experimental utilizado mede $17,0 \mathrm{~m}$ comprimento e $3,5 \mathrm{~m}$ de largura, com uma fileira de gaiola de arame de cada lado, perfazendo um total de 24 gaiolas. As dimensões das gaiolas são $1,0 \mathrm{~m}$ de comprimento; $0,45 \mathrm{~m}$ de 
profundidade e $0,45 \mathrm{~m}$ de altura com divisórias internas de $0,50 \mathrm{~m}$ no sentido do comprimento onde cada compartimento abrigou três aves, totalizando seis por gaiola.

Foram utilizadas 144 poedeiras da linhagem Hissex White com 39 semanas de idade com idênticas condições de alimentação e manejo. Água e ração foram fornecidos ad libitum. A ração em comedouros lineares de alumínio duas vezes ao dia (às 8 e 17 horas) e a água em bebedouros tipo nipple, sendo disponibilizado um por gaiola.

O delineamento experimental aplicado foi o inteiramente casualizado com seis tratamentos constituídos com níveis crescentes de inclusão de farinha de cará $(0,5,10,15,20$ e $25 \%)$ nas rações, e quatro repetições de seis aves cada.

Todas as aves foram pesadas no início do experimento para uniformização das parcelas apresentando peso médio de $1,54 \pm 0,16 \mathrm{~kg}$. A coleta de ovos foi realizada duas vezes ao dia (às 9 e 15 horas) sendo registrada cada ocorrência. Durante todo o período experimental foram fornecidas 16 horas de luz/dia (12 horas natural +4 horas artificial) as aves, com fornecimento de luz artificial nos horários de 20 à 22 horas e 4 à 6 horas, respectivamente. A temperatura $\mathrm{e}$ a umidade relativa do ar foram registrados duas vezes ao dia ( 9 e 15 horas) por meio de um termo higrômetro digital posicionados na altura das aves, com resultados de $34,5 \pm 0,34^{\circ} \mathrm{C}$ e $84,6 \pm 0,78 \%$, respectivamente.

Todo o cará utilizado no experimento foi adquirido na forma in natura de uma só vez junto a feiras e mercados existentes na cidade de Manaus. Após a coleta, foi selecionado o material de melhor aspecto, rejeitando-se o material em decomposição. A seguir, o material foi lavado para retirada de terra, submetido à secagem ao ar durante quatro dias e, posteriormente, triturado em equipamento de trituração de grãos.

A composição centesimal da farinha de cará foi determinada no laboratório de nutrição de peixes do Instituto Nacional de Pesquisas da Amazônia- INPA, conforme metodologias proposta por Silva \& Queiroz (2002) e seus resultados encontram-se na Tabela 1.

As rações foram formuladas utilizando o software computacional Supercrac (2004) em atendimento as exigências nutricionais das aves e conforme os valores dos ingredientes fornecidos pelas Tabelas Brasileiras para Aves e Suínos (ROSTAGNO et al., 2011), com exceção da composição da farinha de cará e encontram-se na Tabela 2.

Tabela 1. Composição centesimal da farinha de cará

\begin{tabular}{lc}
\hline Componentes & Composição \\
\hline Matéria Seca, \% & 95,54 \\
Proteína Bruta, \% & 2,65 \\
Fibra Bruta, \% & 2,69 \\
Fibra Detergente Neutro, \% & 7,45 \\
Fibra Detergente Ácido, \% & 3,64 \\
Gordura, \% & 0,31 \\
Matéria Mineral, \% & 3,23 \\
Extrato Não Nitrogenado, \% & 86,66 \\
Energia Bruta, Kcal/kg & 3730,73 \\
Energia Metabolizável ${ }^{1}, \mathrm{Kcal} / \mathrm{kg}$ & 3489,81 \\
\hline
\end{tabular}

${ }^{\mathrm{l}}$ Foi determinada através do método de cálculo para energia metabolizável aparente conforme descrito por Rostagno et al. (2011), onde obteve-se o valor em $\mathrm{kcal} \mathrm{kg}^{-1}$. 
Rev. Bras. Saúde Prod. Anim., Salvador, v.17, n.3, p.413-423 jul./set., $2016 \quad \underline{\text { http://www.rbspa.ufba.br }}$ ISSN 15199940

Tabela 2. Composições percentual e calculada das rações experimentais

\begin{tabular}{|c|c|c|c|c|c|c|}
\hline \multirow{2}{*}{ Ingredientes } & \multicolumn{6}{|c|}{ Níveis de farinha de cará (\%) } \\
\hline & 0 & 5 & 10 & 15 & 20 & 25 \\
\hline Milho $(7,88 \%)$ & 61,665 & 56,425 & 51,185 & 45,94 & 40,705 & 35,465 \\
\hline F. soja $(46 \%)$ & 25,766 & 25,982 & 26,2 & 26,415 & 26,635 & 26,853 \\
\hline Farinha de cará & 0,000 & 5,000 & 10,000 & 15,000 & 20,000 & 25,000 \\
\hline Calcário calcítico & 9,769 & 9,763 & 9,754 & 9,757 & 9,740 & 9,735 \\
\hline Fosfato bicálcico & 1,695 & 1,710 & 1,725 & 1,739 & 1,756 & 1,769 \\
\hline Suplemento vitamínico e mineral ${ }^{1}$ & 0,500 & 0,500 & 0,500 & 0,500 & 0,500 & 0,500 \\
\hline DL- Metionina (99\%) & 0,255 & 0,270 & 0,286 & 0,299 & 0,314 & 0,328 \\
\hline Sal & 0,350 & 0,350 & 0,350 & 0,350 & 0,350 & 0,350 \\
\hline Total & 100,000 & 100,000 & 100,000 & 100,000 & 100,000 & 100,000 \\
\hline Nutriente & \multicolumn{6}{|c|}{ Níveis nutricionais } \\
\hline E.M, $\mathrm{kcal}^{-1} / \mathrm{kg}$ & $2.678,00$ & $2.686,00$ & $2.694,00$ & $2.702,00$ & $2.710,00$ & $2.718,00$ \\
\hline Proteína bruta, \% & 17,000 & 17,000 & 17,000 & 17,000 & 17,000 & 17,000 \\
\hline Metionina + Cistina, $\%$ & 0,786 & 0,786 & 0,786 & 0,786 & 0,786 & 0,786 \\
\hline Metionina, \% & 0,520 & 0,527 & 0,535 & 0,550 & 0,550 & 0,558 \\
\hline Cálcio, \% & 4,200 & 4,200 & 4,200 & 4,200 & 4,200 & 4,200 \\
\hline Fósforo Disponível, \% & 0,400 & 0,400 & 0,400 & 0,400 & 0,400 & 0,400 \\
\hline Sódio, \% & 0,156 & 0,155 & 0,154 & 0,152 & 0,152 & 0,151 \\
\hline
\end{tabular}

${ }^{\mathrm{I}}$ Níveis de garantia por quilograma de produto: Vitamina A 2.000.000 UI, Vitamina D3 $400.000 \mathrm{UI}$, Vitamina E 2.400mg, Vitamina K3 400mg, Vitamina B1 100mg, Vitamina B2 760mg, Vitamina B6 $100 \mathrm{mg}$, Vitamina B12 2.400mcg, Niacina 5.000mg, Pantotenato de Cálcio $2000 \mathrm{mg}$, Ácido Fólico $50 \mathrm{mg}$, Cocciostático $12.000 \mathrm{mg}$, Colina $50.000 \mathrm{mg}$, Cobre $1.200 \mathrm{mg}$, Ferro $6.000 \mathrm{mg}$, Manganês $14.000 \mathrm{mg}$, Zinco $10.000 \mathrm{mg}$, Iodo $100 \mathrm{mg}$. Selênio $40 \mathrm{mg}$. Veículo Q.S.P. $1.000 \mathrm{~g}$.

No desempenho das aves, a cada período, foram avaliados o consumo de ração (g/ave/dia), produção de ovos $(\%)$, massa de ovo (g), conversão alimentar ( $\mathrm{kg}$ de ração por $\mathrm{kg}$ de ovo produzido) e conversão alimentar ( $\mathrm{kg}$ de ração por dúzia de ovo produzido). Nos dois últimos dias de cada período, foram coletados quatro ovos de cada parcela para mensuração da qualidade do ovo, em que foi avaliado os pesos do ovo (g), do albúmen (g) e da gema (g), alturas do albúmen $(\mathrm{mm})$ e da gema $(\mathrm{mm})$, peso da casca $(\mathrm{g})$, espessura da casca $(\mu \mathrm{m})$, gravidade especifica $\left(\mathrm{g} / \mathrm{cm}^{3}\right)$ e coloração da gema crua. Antes de serem submetidos à avaliação, os ovos foram armazenados durante uma hora a fim de igualar sua temperatura a temperatura ambiente.

Os ovos foram pesados em balança eletrônica com aproximação de $0,01 \mathrm{~g}$.
A massa de ovo foi obtida através do cálculo do quociente entre peso do ovo e a produção de ovos multiplicada por cem. Os ovos inteiros logo após a pesagem foram colocados em cestas de arame e imersos em baldes plásticos contendo diferentes níveis de cloreto de sódio $(\mathrm{NaCl})$, da menor para a maior concentração, com variações de densidade de 1,075 a $1,100 \mathrm{~g} / \mathrm{cm}^{3}$, com intervalo de 0,005 entre elas. Os ovos foram retirados ao flutuarem até a superfície tendo seus valores respectivos anotados.

Para a análise do peso do albúmen e da gema, utilizou-se um separador manual de albúmen e gema. O albúmen e a gema foram colocados em copos plásticos, ambos de peso tarado em balança analítica e pesados. Para calcular altura de albúmen e gema, os mesmos foram colocados sobre uma 
placa plana de vidro para determinação de seus respectivos valores. $\mathrm{O}$ procedimento para mensuração da altura do albúmen e gema consiste em medir na região mediana, entre a borda externa do albúmen e a gema. Para mensuração das alturas foi utilizado um paquímetro eletrônico, tendo os valores em milímetros anotados. O peso da casca do ovo foi obtido após as mesmas serem lavadas, secas à temperatura ambiente por 48 horas e posteriormente pesadas em gramas.

Para a determinação da espessura da casca foram utilizadas as cascas secas, tendo sua leitura feita com o auxílio de um micrômetro. As leituras foram efetuadas em três regiões da casca: basal, meridional e apical, e os valores foram anotados. A partir dos valores obtidos nas três regiões calculou-se a média, em micrometro, da espessura da casca dos ovos. Para avaliação da pigmentação da gema dos ovos, utilizou-se o leque colorimétrico Roche com pontos de 1 a 15 . Para determinação da unidade Haugh utilizou-se a fórmula proposta por Silva (2004).

$\mathrm{Na}$ análise das variáveis relacionadas à bioquímica "sanguínea ou sérica" foram selecionadas quatro aves de cada tratamento, uma por repetição, sendo coletado aproximadamente $3 \mathrm{~mL}$ de sangue da veia ulnar, localizada na asa de cada ave, conforme metodologia proposta por Boettcher (2004). O sangue coletado foi imediatamente enviado ao Laboratório de Tecnologia Avícola do Setor de Avicultura da Universidade Federal do AmazonasUFAM para determinação das concentrações de glicose, triglicerídeos, colesterol e $\mathrm{pH}$ utilizando um analisador bioquímico portátil (Accucheck Trend, ROCHE) com o auxílio de tiras reagentes específicas para cada análise.
Os dados coletados foram submetidos à análise estatística pelo programa computacional Statistical Analysis System (SAS, 2008) e as estimativas dos tratamentos foram submetidas à análise de regressão polinomial à $5 \%$ de significância.

\section{RESULTADOS E DISCUSSÃO}

Os resultados médios obtidos para o desempenho das aves são apresentados na Tabela 3. Foram observadas diferenças significativas $(\mathrm{P}<0,05)$ nos resultados de consumo de ração, produção de ovos, conversão alimentar $(\mathrm{kg} / \mathrm{kg}$ e $\mathrm{kg} / \mathrm{dz})$ e massa de ovo a partir da inclusão de farinha de cará nas rações.

O consumo de ração apresentou efeito quadrático $\left(\mathrm{Y}=0,49 \mathrm{x}^{2}-5,81 \mathrm{x}+\right.$ $115,92)$, onde a partir da derivação da função foi possível estimar o melhor nível de consumo de ração $(98,69 \mathrm{~g} / \mathrm{ave} / \mathrm{dia})$ no nível de 5,92\% em relação aos níveis de farinha de cará. Estes resultados discordam de Braga et al. (2005), que trabalhando com farelo de coco até $20 \%$ de inclusão em rações de poedeiras comerciais, não encontrou diferença significativa para $\mathrm{o}$ desempenho produtivo.

Verifica-se uma associação entre à quantidade energética elevada nas rações a partir inclusão de farinha de cará, com as alterações alimentares relacionadas ao ajuste de consumo realizado pelas poedeiras. Grobas et al. (2001) e Freitas et al. (2013), em seus estudos indicam que alterações mínimas na relação energia-proteína nas dietas, associadas com a quantidade de alimento ingerido voluntariamente de acordo com à palatabilidade da ração, podem ocasionar decréscimos 
significativos no desempenho produtivo das poedeiras.

A produção de ovos apresentou efeito quadrático, onde com a derivação da equação de regressão $\left(\mathrm{Y}=3,9 \mathrm{x}^{2}\right.$ $11,04 \mathrm{x}+87,26)$ verificou-se o percentual ideal de produção $(79,44 \%)$ ao nível de $1,41 \%$ de inclusão de farinha de cará nas rações. Entre os fatores que podem afetar a produção de ovos, destaca-se a ingestão de alimento e consequentemente a ingestão de energia e proteína pelas aves (FREITAS et al., 2005). Cruz et al. (2006) e Lima et al. (2007) não encontraram diferenças significativas para a produção de ovos trabalhando com apara de mandioca e farelo de coco, respectivamente, como fonte energética a partir da inclusão de alimentos com alto teor de carboidratos livres nas rações.

Tabela 3. Consumo de ração (CR), conversão alimentar quilo de ração por dúzia de ovos $(\mathrm{CA}, \mathrm{kg} / \mathrm{dz})$, conversão alimentar quilo de ração por quilo de ovo (CA, $\mathrm{kg} / \mathrm{kg}$ ), massa de ovo (MO) e percentagem de postura (PERCP) de poedeiras alimentadas com rações contendo níveis farinha do cará

\begin{tabular}{|c|c|c|c|c|c|c|c|c|c|}
\hline \multirow{2}{*}{ Variáveis } & \multicolumn{6}{|c|}{ Níveis de inclusão de farinha de cará (\%) } & \multirow{2}{*}{ P Valor } & \multirow{2}{*}{$\mathrm{R}^{2}$} & \multirow{2}{*}{$\begin{array}{l}\text { CV } \\
(\%)\end{array}$} \\
\hline & 0 & 5 & 10 & 15 & 20 & 25 & & & \\
\hline CR, g/ave/dia* & 108,19 & 110,81 & 103,90 & 94,67 & 102,14 & 98,81 & 0,04 & 0,41 & 4,07 \\
\hline PERCP, \%* & 75,40 & 71,20 & 51,60 & 53,00 & 41,20 & 35,20 & 0,05 & 0,64 & 13,15 \\
\hline $\mathrm{CA}, \mathrm{kg} / \mathrm{kg}^{*}$ & 2,59 & 2,82 & 3,97 & 3,31 & 5,57 & 5,76 & 0,04 & 0,37 & 10,43 \\
\hline $\mathrm{CA}, \mathrm{kg} / \mathrm{dz}^{*}$ & 1,46 & 1,58 & 2,11 & 1,80 & 3,13 & 3,21 & 0,04 & 0,36 & 12,25 \\
\hline $\mathrm{MO}, \mathrm{g}^{*}$ & 44,00 & 41,30 & 28,77 & 30,15 & 23,96 & 20,02 & 0,01 & 0,66 & 15,31 \\
\hline
\end{tabular}

$\mathrm{CV}=$ coeficiente de variação; *Efeito quadrático; $\mathrm{P}$ Valor $=$ coeficiente de probabilidade; $\mathrm{R}^{2}=$ coeficiente de determinação.

$\mathrm{Na}$ conversão alimentar $(\mathrm{kg} / \mathrm{kg})$ verificou-se efeito quadrático $(\mathrm{Y}=$ $\left.0,076 \mathrm{x}^{2}+0,13 \mathrm{x}+2,37\right)$, com a derivação da função apresentando $o$ ponto de melhor conversão $(2,42 \mathrm{~kg} / \mathrm{kg})$ ao nível $0,85 \%$ de farinha de cará nas rações. A conversão alimentar $(\mathrm{kg} / \mathrm{dz})$ apresentou efeito quadrático $(\mathrm{Y}=$ $\left.0,053 \mathrm{x}^{2}+0,00066 \mathrm{x}+1,40\right)$, sendo que a melhor conversão $(1,4 \mathrm{~kg} / \mathrm{dz})$ obtida com a inclusão de $0,06 \%$ de farinha de cará. As conversões alimentares $(\mathrm{kg} / \mathrm{kg}$ e $\mathrm{kg} / \mathrm{dz}$ ) apresentaram piores resultados à medida que aumentou o nível de farinha de cará nas rações, acarretando juntamente consigo queda significativa na produção de ovos. Estes resultados corroboram com os obtidos por Araújo et al. (2008) que trabalhando com farelo de trigo com boa disponibilidade de energia e carboidratos livres ao milho obtiveram alterações significativas no desempenho de poedeiras comerciais.

A massa de ovo foi influenciada significativamente pela inclusão de farinha de cará nas rações, onde verificou-se efeito quadrático $(\mathrm{Y}=$ $\left.0,34 \mathrm{x}^{2}-7,27 \mathrm{x}+51,62\right)$, com a derivação da função apresentando a melhor massa de ovo $(47,73 \mathrm{~g})$ ao nível de $1,069 \%$ de inclusão de farinha de cará. Estes resultados corroboram com Costa et al. (2009), que em trabalho desenvolvido com raspa de mandioca em rações de poedeiras encontraram efeito significativo para massa de ovo a partir da inclusão de alimentos alternativos tuberosos nas rações. Os 
resultados obtidos para massa de ovo culminaram consequentemente dos efeitos observados sobre a produção de ovos, uma vez que este resultado apresenta-se como fator de influência no cálculo da massa de ovo juntamente com o peso do ovo.

Os resultados médios obtidos para as variáveis relacionadas a qualidade do ovo das aves são apresentados na Tabela 4. As variáveis relacionadas a qualidade do ovo não apresentaram diferenças significativas $(\mathrm{P}>0,05)$ a partir da adição de níveis de farinha do cará nas rações. Esses resultados discordam de Miller et al. (2013) que trabalhando com a inclusão de resíduo de tucumã até $25 \%$ em rações para poedeiras leves, observou que diferenças significativas $(\mathrm{P}<0,05)$ para a percentagem de albúmen, espessura de casca e pigmentação de gema.

Os resultados obtidos para pigmentação da gema, segundo Carvalho et al. (2006), são alterados pelos índices de carotenóides da dieta. Porém, a utilização ou não de pigmentantes naturais ou artificiais irá depender da finalidade da criação, bem como dos consumidores finais do produto, assim a utilização de cará na ração de poedeiras não afetou estes resultados.

Com relação à casca do ovo, são vários os fatores que podem afetar sua qualidade, entre eles o teor de gordura na dieta (BRITO et al., 2009). Rações muito gordurosas, principalmente contendo a presença de alimentos tuberosos, podem reduzir a absorção e a retenção de minerais como cálcio e fósforo, afetando negativamente a qualidade da casca do ovo, mesmo que não sejam alterações significativas conforme afirmam Pinheiro et al. (2012) e Nogueira et al. (2014).

$\mathrm{Na}$ unidade Haugh, como medida de qualidade do ovo, os resultados obtidos corroboram com Harder et al. (2008) e Brunelli et al. (2010) que também não encontraram influência da dieta na altura do albúmen, e com Loureiro et al. (2007), que, ao fornecerem rações com até $20 \%$ de farelo de tomate para poedeiras, também observaram ausência de efeito significativo, porém, com queda na qualidade do ovo.

Tabela 4. Peso do ovo (PO), percentagem de albúmen (PERCA), percentagem de gema (PERCG), percentagem de casca (PERCC), altura do albúmen (AA), altura da gema (AG), espessura da casca (EC), gravidade específica (GE), Unidade Haugh e pigmentação da gema crua (PG) do ovo de poedeiras alimentadas com rações contendo níveis farinha do cará

\begin{tabular}{|c|c|c|c|c|c|c|c|c|c|}
\hline \multirow{2}{*}{ Variáveis } & \multicolumn{6}{|c|}{ Níveis de inclusão de farinha do cará (\%) } & \multirow{2}{*}{ P Valor } & \multirow{2}{*}{$\mathrm{R}^{2}$} & \multirow{2}{*}{ CV $(\%)$} \\
\hline & 0 & 5 & 10 & 15 & 20 & 25 & & & \\
\hline $\mathrm{PO}, \mathrm{g}$ & 58,52 & 58,11 & 55,65 & 56,85 & 58,38 & 57,47 & 0,59 & - & 4,40 \\
\hline PERCA, \% & 60,22 & 59,88 & 60,69 & 59,46 & 60,32 & 58,67 & 0,89 & - & 4,29 \\
\hline PERCG, $\%$ & 27,45 & 27,74 & 27,28 & 27,75 & 27,93 & 27,43 & 0,98 & - & 5,32 \\
\hline $\mathrm{AA}, \mathrm{mm}$ & 4,46 & 4,62 & 4,91 & 4,89 & 4,75 & 5,14 & 0,12 & - & 6,98 \\
\hline $\mathrm{AG}, \mathrm{mm}$ & 15,60 & 16,29 & 15,60 & 16,06 & 16,30 & 16,06 & 0,22 & - & 3,19 \\
\hline PERCC, \% & 10,84 & 11,34 & 11,51 & 11,52 & 10,99 & 11,23 & 0,13 & - & 3,51 \\
\hline $\mathrm{EC}, \mu \mathrm{m}$ & 44,50 & 44,00 & 41,75 & 43,25 & 45,25 & 46,50 & 0,19 & - & 5,75 \\
\hline GE., g/mL & 1090,00 & 1094,06 & 1092,81 & 1092,50 & 1090,94 & 1094,69 & 0,16 & - & 0,25 \\
\hline $\mathrm{UH}$ & 63,13 & 62,69 & 60,16 & 61,36 & 62,92 & 61,92 & 0,57 & - & 4,11 \\
\hline PG & 5,69 & 5,31 & 5,25 & 5,06 & 4,79 & 4,87 & 0,12 & - & 8,98 \\
\hline
\end{tabular}

$\mathrm{CV}=$ coeficiente de variação; $\mathrm{P}$ Valor $=$ coeficiente de probabilidade; $\mathrm{R}^{2}=$ coeficiente de determinação. 
Os resultados obtidos para as variáveis relacionadas aos parâmetros bioquímicos estão dispostos na Tabela 5. Foram encontradas diferenças significativas $(\mathrm{P}<0,05)$ para resultados médios de triglicerídeos e $\mathrm{pH}$ sanguíneo a partir da adição de diferentes níveis de farinha do cará nas rações.

Os resultados para triglicerídeos apresentaram efeito quadrático $(\mathrm{Y}=$ $\left.35,56 x^{2}+288,08 x-103,77\right)$, onde a partir da derivação da função estimou-se a maior concentração de triglicerídeos no sangue $\left(479,68 \mathrm{mg} / \mathrm{dl}^{-1}\right)$ ao nível de $4,05 \%$ de farinha de cará nas rações.
A partir da inclusão da farinha de cará na dieta, verificou-se aumento na concentração de triglicerídeos sanguíneos, onde de acordo com Klasing (1998) e Borsa et al. (2006), a partir do advento do metabolismo mais acelerado das poedeiras quando submetidas a dietas com elevados níveis de energia, estas exigem maior mobilização de ácidos graxos e hormônios esteroides para síntese de gema e outras funções metabólicas, causando alterações significativas na concentração de triglicerídeos totais na corrente sanguínea.

Tabela 5. Valores de glicose (GLI), triglicerídeos (TRIG), colesterol (COL) e pH de poedeiras alimentadas com rações contendo diferentes níveis farinha do cará

\begin{tabular}{|c|c|c|c|c|c|c|c|c|c|}
\hline \multirow{2}{*}{ Variáveis } & \multicolumn{6}{|c|}{ Níveis de inclusão de farinha de cará (\%) } & \multirow{2}{*}{$\begin{array}{c}\mathrm{P} \\
\text { Valor }\end{array}$} & \multirow{2}{*}{$\mathrm{R}^{2}$} & \multirow{2}{*}{$\begin{array}{c}\mathrm{CV} \\
\%\end{array}$} \\
\hline & 0 & 5 & 10 & 15 & 20 & 25 & & & \\
\hline GLI, $\mathrm{mg} / \mathrm{dl}^{-1}$ & 180,00 & 133,00 & 177,50 & 148,50 & 160,75 & 163,25 & 0,20 & - & 17,43 \\
\hline TRIG, $\mathrm{mg} / \mathrm{dl}^{-1} *$ & 121,25 & 391,00 & 424,00 & 438,20 & 473,00 & 343,00 & 0,01 & 0,73 & 17,78 \\
\hline $\mathrm{COL}, \mathrm{mg} / \mathrm{dl}^{-1}$ & 178,75 & 181,25 & 183,50 & 181,00 & 182,00 & 173,00 & 0,49 & - & 4,33 \\
\hline $\mathrm{Ph}^{*}$ & 6,79 & 6,84 & 6,93 & 7,08 & 7,10 & 7,13 & 0,01 & 0,52 & 1,88 \\
\hline
\end{tabular}

$\mathrm{CV}=$ Coeficiente de variação; *Efeito quadrático; $\mathrm{P}$ Valor $=$ coeficiente de probabilidade; $\mathrm{R}^{2}=$ coeficiente de determinação.

Os resultados de $\mathrm{pH}$ também apresentaram efeito quadrático (Y= $\left.0,013 x^{2}+0,16 x+6,60\right)$, com derivação da equação possibilitando estimar o maior valor de $\mathrm{pH}(7,09)$ no nível de $6,15 \%$ de farinha de cará. Observou-se que $\mathrm{o} \mathrm{pH}$ sanguíneo elevou-se à medida que aumentou-se os níveis de farinha do cará nas rações, o que denota a sensibilidade do metabolismo sanguíneo das aves a inclusão acentuada de carboidratos livres na dieta, dos quais a farinha de cará é rica, e possíveis alterações metabólicas que podem ocorrer no equilíbrio ácido-básico sanguíneo destas (SUMMERS et al., 1987; MINAFRA et al., 2010).
Apesar de não apresentarem diferenças significativas $(\mathrm{P}>0,05)$, as concentrações médias de glicose e colesterol total encontram-se dentro dos valores de referência de 130 a $270 \mathrm{mg} / \mathrm{dl}^{-1}$ e de 125 a $200 \mathrm{mg} / \mathrm{dl}^{-1}$ (KANEKO et al., 1997), respectivamente.

A partir dos resultados encontrados, conclui-se, portanto, que a farinha de cará pode ser utilizada como alimento alternativo em rações de poedeiras comerciais leves, tendo o nível de $5 \%$ de inclusão apresentado melhor desempenho e resultados de bioquímica sérica. Até $25 \%$ de inclusão, não houve alteração na qualidade do ovo. 
Rev. Bras. Saúde Prod. Anim., Salvador, v.17, n.3, p.413-423 jul./set., $2016 \quad$ http://www.rbspa.ufba.br ISSN 15199940

\section{REFERÊNCIAS}

ARAÚJO, D.M.; SILVA, J.H.V.; ARAÚJO, J.A.; TEXEIRA, E.N.M.; FILHO, J.J.; RIBEIRO, M.L.G. Farelo de trigo na alimentação de poedeiras semipesadas na fase de recria. Revista Brasileira de Zootecnia, v.37, n.1, p.67-72, 2008.

BORSA, A.; KOHAYAGAWA, A.; BORETTI, L.P.; SAITO, M.E.; KUIBIDA, K. Serum levels of hepatic enzyme function in clinically healthy broiler chickens. Arquivo Brasileiro de Medicina Veterinária e Zootecnia, v.58, n.4, p.675-677, 2006.

BRAGA, C.V.P.; FUENTES, M.F.F.; FREITAS, E.R.; CARVALHO, L.E.; SOUSA, F.M.; BASTOS, S.C. Efeito da inclusão do Farelo de coco em rações para poedeiras comerciais. Revista Brasileira de Zootecnia, v.34, n.1, p.76-80, 2005.

BRITO, A.B.; STRINGHINI, J.H.; XAVIER, S.A.G.; CAFÉ, M.B.; LEANDRO, N.S.M. Desempenho e qualidade dos ovos de poedeiras comerciais no segundo ciclo de produção consumindo gérmen integral de milho. Revista Brasileira de Zootecnia, v.38, n.10, p.1907-1913, 2009.

BOETTCHER, A. Valores bioquímicos sanguíneos del cisne de cuello negro (Cygnus melanocoryphus, Molina 1782), en una población silvestre, de Valdivia, Chile. Valdivia: Universidad Austral de Chile, 2004

BRUNELLI, S.R.; PINHEIRO, J.W.; FONSECA, N.A.N.; OBA, A.; SILVA, C.A. Farelo de gérmen de milho desengordurado na dieta de poedeiras comerciais de 28 a 44 semanas de idade. Revista Brasileira de Zootecnia, v.39, n.5, p.1068-1073, 2010.

CARVALHO, P.R.; PITA, M.C.G.; PIBER-NETO, E.; MIRANDOLA, R.M.S.; MENDONÇA JUNIOR, C.X. Influência da adição de fontes marinhas de carotenóides à dieta de galinhas poedeiras na pigmentação da gema do ovo. Brazilian Journal of Veterinary Research and Animal Science, v.43, n.5, 2006.

COSTA, F.G.P.; GOULART, C.C.; COSTA, J.S.; SOUZA, C.J.; BARROS, L.R.; SILVA, J.H.V. Desempenho, qualidade de ovos e análise econômica da produção de poedeiras semipesadas alimentadas com diferentes níveis de raspa de mandioca. Acta Scientiarum. Animal Sciences, v.31, n.1, p.13-18, 2009.

CRUZ, F.G.G.; PEREIRA FILHO, M.; CHAVES F.A.L. Efeito da substituição do milho pela farinha da apara de mandioca em rações para poedeiras comerciais. Revista Brasileira de Zootecnia, v.35, n.6, p.2303-2308, 2006.

FREITAS, A.C.; FUENTES, M.F.F.; FREITAS, E.R.; SUCUPIRA, F.S.; OLIVEIRA, B.C.M. Efeito de níveis de proteína bruta e de energia metabolizável na dieta sobre o desempenho de codornas de postura. Revista Brasileira de Zootecnia, v.34, n.3, p.838-846, 2005.

FREITAS, E.R.; BORGES, A.S.; TREVISAN, M.T.S.; CUNHA, A.L.; BRAZ, N.M.; WATANABE, P.H.; NASCIMENTO, G.A.J. Extratos etanólicos de manga como antioxidantes na alimentação de poedeiras. Pesquisa Agropecuária Brasileira, v.48, n.7, p.714-721, 2013. 
Rev. Bras. Saúde Prod. Anim., Salvador, v.17, n.3, p.413-423 jul./set., $2016 \quad \underline{\text { http://www.rbspa.ufba.br }}$ ISSN 15199940

GARCIA, A.R.; DALE, N.M. Feeding of underground pearl millet to laying hens. Poultry Science, v.15, p.574-578, 2006.

GARCIA, E.A.; MOLINO, A.B.; BERTO, D.A.; PELÍCIA, K.; OSERA, R.H.; FAITARONE, A.B.G.

Desempenho e qualidade dos ovos de poedeiras comerciais alimentadas com semente de urucum (Bixa orellana L.) moída na dieta. Veterinária e

Zootecnia, v.16, n.4, p.689-697, 2009.

GROBAS, S.; MÉNDEZ, J.; LÁZARO, R.; BLAS, C.; MATEOS, G.G.

Influence of source and percentage of fat added to diet on performance and fatty acid composition of egg yolks of two strains of laying hens. Poultry Science, v.80, p.1171-1179, 2001.

HARDER, M.N.C.; BRAZACA, S.G.C.; SAVINO, V.J.M.; COELHO, A.A.D. Efeito de Bixa orellana na alteração de características de ovos de galinhas. Ciência Agrotécnica, v.32, n.4, p.1232-1237, 2008.

JAFARI, M.; PIRMOHAMMADI, R.; BAMPIDIS, V. The use of dried tomato pulp in diets of laying hens.

International Journal of Poultry

Science, v.5, n.7, p.618-622, 2006.

KANEKO, J; HARVEY, J; BRUSS, M. Clinical Biochemistry of Domestic Animals, 5th ed. San Diego: Academic Press, 1997. 932p.

KLASING, K.C. Comparative avian nutrition. Wallingford: $\mathrm{CAB}$ International, 1998. 350p.

LIMA, R.C.; FUENTES, M.F.F.; FREITAS, E.R.; SUCUPIRA, F.S.; MOREIRA, R.F.; BRAZ, N.M. Farelo de coco na ração de poedeiras comerciais: digestibilidade dos nutrientes, desempenho e qualidade dos ovos. Revista Brasileira de Zootecnia, v.36, n.5, p.1340-1346, 2007.

LOPES, I.R.V.; FREITAS, E.R.; LIMA, J.R.; NETO, J.L.V.; BEZERRA, R.M.; LIMA, R.C. Desempenho e qualidade dos ovos de poedeiras comerciais alimentadas com rações contendo farelo de coco tratado ou não com antioxidante. Revista Brasileira de Zootecnia, v.40, n.11, p.2431-2438, 2011.

LOUREIRO, R.R.S.; RABELLO, C.B.V.; LUDKE, J.V.; JUNIOR, W.M.D.; GUIMARÃES, A.A.S.; SILVA, J.H.V. Farelo de tomate (Lycopersicum esculentum Mill.) na alimentação de poedeiras comerciais. Acta Scientarium. Animal. Sciences, v.29, n.4, p.387-394, 2007.

MILLER, W.M.P.; CRUZ, F. G. G.; CHAGAS, E.O.; SILVA, A.F.; ASSANTE, R.T.; Farinha do resíduo de tucumã (Astrocaryum vulgare Mart.) na alimentação de poedeiras. Revista Acadêmica Ciência Animal, v.11, n.1, p.105-114, 2013.

MINAFRA, C.S.; MARQUES, S.F.F.; STRINGHINI, J.H.; ULHOA, C.J.; MINAFRA E RESENDE, C.S.; SANTOS, J.S.; MORAES, G.H.K. Perfil bioquímico do soro de frangos de corte alimentados com dieta suplementada com alfa-amilase de Cryptococcus flavus e Aspergillus niger HM2003. Revista Brasileira de Zootecnia, v.39, n.12, p.2691-2696, 2010.

NOGUEIRA, M.A.; CRUZ, F.G.G.; TANAKA, E.S.; RUFINO, J.P.F.; SANTANA, T.M. Óleo de dendê (Elaeais guineensis Jaquim) na alimentação de poedeiras leves. Revista Acadêmica de Ciências Agrárias e Ambientais, v.12, n.2, p.103-111, 2014. 
Rev. Bras. Saúde Prod. Anim., Salvador, v.17, n.3, p.413-423 jul./set., $2016 \quad \underline{\text { http://www.rbspa.ufba.br }}$

PINHEIRO, J.W.; FONSECA, N.A.N.; BRIDI, A.M.; DA SILVA, C.A.; OBA, A.; MEDEIROS, L.G.; OLIVEIRA, M.L.L. Desempenho e qualidade dos ovos de poedeiras comerciais leves submetidas a dietas contendo torta de nabo forrageiro (Raphanus sativus).

Semina: Ciências Agrárias, v.33, n.4, p.1555-1564, 2012.

RAMOS-ESCUDERO, F.; SANTOSBUELGA, C.; PÉREZ-ALONSO, J.J.; YÁNES, J.A.; DUENAS, M. HPLCESI/MS identification of anthocyanins in Dioscorea trifida L. yam tuber (purple sachapapa). European Food Research and Technology, v.230, p.745-752, 2010.

ROSTAGNO, H.S.; ALBINO, L.F.T.; DONZELE, J.L.; GOMES, P.C.; OLIVEIRA, R.F.; LOPES, D.C.; FERREIRA, A.S.; BARRETO, S.L.T.; EUCLIDES, R.F. Tabelas brasileiras para aves e suínos: composição de alimentos e exigências nutricionais. Viçosa: Universidade Federal de Viçosa, 2011.252p.

SANTOS, J.F.; GRANGEIRO, J.I.T. Desempenho de aves caipiras de corte alimentadas com mandioca e palma forrageira enriquecidas com levedura. Tecnologia \& Ciência Agropecuária, v.6, n.2, p.49-54, 2012.

SILVA, F.H.A. Curso teórico-prático sobre técnicas básicas de avaliação de qualidade do ovo. Piracicaba: ESALQ, 2004.

SILVA, D.J.; QUEIROZ, A.C. Análise de alimentos: métodos químicos e biológicos. 3.ed. Viçosa: Universidade Federal de Viçosa, 2002. 235p.
SILVA, E.P.; RABELLO, C.B.V; DUTRA-JUNIOR, W.M.; LOUREIRO, R.R.S.; GUIMARÃES, A.A.S.; LIMA, M.B.; ARRUDA, E.M.F.; LIMA, R.B. Análise econômica da inclusão dos resíduos de goiaba e tomate na ração de poedeiras comerciais. Revista Brasileira de Saúde e Produção Animal [online], v.10, n.4, p.774-785, 2009.

Supercrac. Ração de custo mínimo. Versão 1.02 para Windows. [S.I]: TD Software, 2004.

SAS. Statistical Analysis System. SAS/STAT Software Version 9.2. Cary: SAS Institute Inc., 2008.

SUMMERS, J.D., BEDFORD, M., SPRATT, D. Sudden death syndrome: is it a metabolic disease? Feedstuffs, v.26, p.20-23, 1987.

Data de recebimento: 08/04/2015

Data de aprovação: 06/06/2016 